the top line of its website (accessed March 2015) states 'PLEASE NOTE: We are sorry that we are unable to accept new referrals for London residents at this time due to unprecedented demand for services' ${ }^{5}$ - ie lack of resources.

Which brings in the issue of finance. The London PHP is financed by approximately $£ 1.2$ million yearly from the London Specialised Commissioning Group. The GMC's review suggests a nationwide annual price tag of approximately $\mathfrak{E} 6$ million for the service and speculates on where that might be raised, recommending national support (Department of Health, NHS England and the devolved administrations) for two years to set up the scheme, and subsequent funding from the GMC by a potential $5 \%$ increase in the annual retention fee or possibly from existing GMC income. ${ }^{3}$ Strong reactions may be anticipated to some of these suggestions, but should not prevent the development of a service which will not only help doctors but, judging from the success of the London project, help protect the quality of care they provide.

\section{References}

1 RCP. Work and wellbeing in the NHS: why staff health matters to patient care. London: RCP, 2015.

2 Harrison R, Lawton R, Stewart K. Doctors 'experiences of adverse events in secondary care: the professional and personal impact. Clin Med 2014;14:585-90.

3 Horsfall S. Doctors who commit suicide while under GMC fitness to practise investigation: Internal review. London: General Medical Council, 2014.

4 Meltzer H, Griffi ths C, Brock A et al. Patterns of suicide by occupation in England and Wales: 2001-2005. Br J Psychiatry 2008;193:73-6.

5 Practitioner Health Programme. NHS practitioner Health Programme. Available online at http://php.nhs.uk/ [Accessed 25 March 2015].

6 Practitioner Health Programme. PHP Annual Reports. Available online at http://php.nhs.uk/resources/php-annual-reports/ [Accessed 25 March 2015].

Humphrey Hodgson

\title{
Registration at the time of graduation
}

\author{
Author: Peter Kopelman ${ }^{\mathrm{A}}$
}

The point at which the General Medical Council (GMC) grants registration to newly qualified doctors has been debated for some while. At the heart of this is patient safety.

In 1968, the Royal Commission on Medical Education endorsed the approach of the Goodenough Committee, twenty years earlier, which expressed concern about the experience and clinical competence of newly graduated doctors and advocated a supervised preregistration year after graduation from medical school. ${ }^{1,2}$ The preregistration year is now incorporated as the first year of Foundation Programme (FY1) and is regarded as a key component of the start of postgraduate medical training in the UK.

The expansion of medical student numbers and medical schools in England have raised concerns about the prospect of medical graduates finding themselves both unemployed and unemployable if they fail to secure a FY1 post. At first sight moving GMC full registration to the time of graduation would overcome this. ${ }^{3}$ It would additionally address the question of who actually has oversight of doctors in the first year of the Foundation Programme by enabling those overseeing postgraduate medical education to take full responsibility rather than sharing this with medical schools whose graduate may be working in a distant part of the UK. Changing the timing furthermore will potentially provide UK Health Services with a greater opportunity to regulate the numbers of doctors they wish to fund and train at any one time. But this would not address the risks of medical unemployment among those just qualified because the

Author: Aprincipal, St George's, University of London, London, UK competition for FY1 places may significantly increase. Moving the timing of registration will open eligibility to the Foundation Programme for all newly registered doctors in Europe rather than the current limitation to those countries that have comparable schemes of internship.

The Medical Schools Council has welcomed the announcement by the undersecretary for health of a 'stakeholder engagement period' on moving the point of registration but acknowledges that 'such a move raises complex issues that will need to be addressed during the proposed engagement process'. ${ }^{4}$

The four most pressing issues to my mind are: preparedness of graduates for clinical practice; practical prescribing abilities of a new graduate; the alignment with the Professional and Linguistic Assessments Board (PLAB) examination or any future national qualifying examination; and the compliance of UK graduate entry to medicine with EU law.

Medical students are undoubtedly better prepared for clinical practice today than in the past. However, the opportunities for practical rather than simulated experience of responsibility and management of patient care are restricted as a medical student. The GMC appropriately considers that the majority of invasive investigative and therapeutic interventions should await qualification. This understandably results in newly qualified doctors expressing a concern about how well they feel prepared for the practical elements and responsibilities of a FY1 doctor. Such concern varies between students from different medical schools and is unrelated to how closely they consider that they are supervised in clinical settings. ${ }^{5-9}$

A number of recent studies (most notably the GMC's EQUIP study) have raised questions about errors in prescribing by 
doctors during the Foundation Programme. ${ }^{10-15}$ These are more readily identified because prescribing in the pre-registration year is only permitted in the supervised environment of hospital practice - alternative measures for supervision will be essential if the timing of registration is brought forward.

Currently there is explicit recognition of the equivalence of standards required by the GMC for all doctors wishing to secure full registration. Doctors applying for full registration with the GMC are those who have completed a UK primary medical qualification (PMQ) and the FY1 year; those who have completed an EEA PMQ and an internship year (or FY1 year); or those doctors who are international medical graduates who have passed PLAB. The PLAB test is the main route by which international medical graduates demonstrate that they have the necessary knowledge and skills to practise medicine in the UK. ${ }^{14}$ If full registration were to be granted at the completion of a PMQ (without completing FY1 or an internship year), the current standard set for PLAB would no longer be equivalent to UK and EEA applicants for full registration. This would require the lowering of the PLAB standard to the level of completion of $\mathrm{PMQ}$, a move that may not meet broad acceptance. The potential dilemma around equivalence of standards will only be answered through the introduction of a national licensing examination that all doctors are required to take to secure a licence to practise and employment in the UK. This is under active consideration by the GMC but its nature, context and timing have yet to be agreed.

The fourth concern is the impact of the timing of registration on graduate entry medical programmes. There are $16 \mathrm{UK}$ medical schools that currently accept graduates to shortened programmes of medical training (4 years). A number of programmes, led by St George's, accept graduates from disciplines other than sciences, provided they achieve a specified standard in a pre-entry assessment of scientific knowledge, such as the Graduate Australian Medical Admissions Test, GAMSAT. ${ }^{15}$ Those medical schools that run graduate entry programmes (GEPs) agree that these students bring additional maturity and experience to medical training that enriches the course and provides benefit to other students and patients. It is noteworthy that at St George's, many more GEP students compared with the five-year school-leaver programme express an immediate desire to enter general practice, which is particularly important when the NHS faces a serious a shortfall in the recruitment of GPs. Moving registration to the time of graduation puts medical GEPs at serious risk because they will no longer fulfil the EU Directive that requires five years and 5,500 hours of study. ${ }^{16}$ Presently, the inclusion of FY1 provides the fifth year of study. The expectation that graduates will wish to follow a five-year undergraduate programme and bear the burden of additional debt (they are not entitled to a student loan) is refuted by a recent survey at St George's of GEP students and newly qualified doctors.

All of this highlights the importance of risk mitigation and a greater degree of pragmatism prior to the abolition of the provisional registration year by moving the point of registration. Just as Goodenough identified 70 years ago, the starting point must be the safety of the patient and the quality of medical education. Any change must not be pursued simply as a means for balancing supply and demand of the medical workforce. The change to primary legislation, which will be required, inevitably will take several years to enact and is not the 'quick fix' possibly perceived by some. I suspect that the resolution to these complex issues requires much more time and thought, a better understanding of the implications of a national licensing examination, and an opportunity to engage the medical profession taking heed of concerns expressed by those in current undergraduate and postgraduate training, rather than those established in the medical hierarchy.

\section{References}

1 The Royal Commission. Report of the Royal Commission on Medical Education, 1965-68. London: HMSO, 1968.

2 Goodenough W (Chair). Report of the inter-departmental committee on medical schools. London: HMSO, 1944.

3 Health Education England. Engagement exercise announced on point of medical registration. London: NHS, 29 January 2015. Available online at http://hee.nhs.uk/2015/01/29/stakeholder-engagementexercise-announced/ [Accessed 5 March 2015].

4 Medical Schools Council. Medical Schools Council welcomes engagement on moving the point of registration. London: Medical Schools Council, 30 January 2015. Available online at www.medschools.ac. uk/News/Pages/Medical-Schools-Council-welcomes-engagement-onmoving-the-point-of-registration.aspx [Accessed 5 March 2015].

5 Goldacre MJ, Lambert T, Evans J, Turner G. Preregistration house officers' views on whether their experience at medical school prepared them well for their jobs: national questionnaire survey. BMJ 2003;326:1011-2.

6 Goldacre MJ, Taylor K, Lambert TW. Views of junior doctors about whether their medical school prepared them well for work: questionnaire surveys. BMC Med Educ 2010:78.

7 Goldacre MJ, Lambert TW, Svirko E. Foundation doctors' views on whether their medical school prepared them well for work: UK graduates of 2008 and 2009. Postgrad Med J 2014;90:63-8.

8 General Medical Council. Preparing doctors through medical education and training. In: The state of medical education and practice in the UK. London: GMC 2014. Available online at www.gmc-uk.org/ SoMEP_chapter_3.pdf_58053779.pdf [Accessed 5 March 2015].

9 General Medical Council. Be prepared: are new doctors safe to practise? London: GMC, 2014. Available online at www.gmc-uk.org/ Be_prepared__are_new_doctors_safe_to_practise_Oct_2014. pdf_58044232.pdf [Accessed 5 March 2015].

10 Dornan T, Ashcroft D, Heathfield $\mathrm{H}$ et al. An in depth investigation into causes of prescribing errors by foundation trainees in relation to their medical education. EQUIP study. London: GMC, 2009. Available online at www.gmc-uk.org/FINAL_Report_prevalence_and_causes_ of_prescribing_errors.pdf_28935150.pdf [Accessed 5 March 2015].

11 Heaton A, Webb DJ, Maxwell SR. Undergraduate preparation for prescribing: the views of 2413 UK medical students and recent graduates. Br J Clin Pharmacol 2008; 66:128-34.

12 Seden K, Kirkham JJ, Kennedy T et al. Cross-sectional study of prescribing errors in patients admitted to nine hospitals across North West England. BMJ Open 2013;3:e002036.

13 Ryan C, Ross S, Davey P et al. Prevalence and causes of prescribing errors: the PRescribing Outcomes for Trainee Doctors Engaged in Clinical Training (PROTECT) study. PLoS One 2014;9:e79802.

14 General Medical Council. GMC Professional and Linguistics Assessments Board. Available online at www.gmc-uk.org/doctors/plab.asp [Accessed 9 March 2015].

15 Australian Council for Educational Research. Graduate medical school admissions test. Available online at www.gamsat-ie.org/ [Accessed 9 March 2015].

16 European Commission. European Directive Basic Medical education. Available online at http://ec.europa.eu/growth/single-market/ services/qualifications/policy-developments/legislation/index_en. htm [Accessed 5 March 2015].

Address for correspondence: Prof P Kopelman, St George's, University of London, Cranmer Terrace, London SW17 ORE, UK. Email: pkopelman@sgul.ac.uk 